\title{
A Physico-Chemical Study of the Cationic Surfactants Adsorption on Montmorillonite
}

\author{
Petr Praus* and Martina Turicová \\ Department of Analytical Chemistry and Material Testing, VSB-Technical University Ostrava, 17. \\ listopadu 15, 70833 Ostrava, Czech Republic
}

\begin{abstract}
O objetivo deste trabalho é o estudo da adsorção de brometo de cetiltilmetilamônio (CTA) e de cloreto de cetilpiridínio (CP) em argilas do tipo montorilonita (MMT) ricas em sódio. Um método isotacoforético (ITP) específico foi desenvolvido visando à determinação rápida e simultânea dos surfatantes catiônicos (CS) adsorvidos. A fim de reduzir os limites de detecção, o método isotacoforético foi conjugado com a técnica de eletroforese capilar. Para determinar o arranjo dos surfatantes catiônicos (CS) adsorvidos na superfície das argilas foi efetuada a avaliação do balanço molar entre os surfatantes e os cátions metálicos juntamente com as isotermas de adsorção. A maior adsorção do CP comparada a do CTA pode ser entendida não só pela ação das forças eletrostáticas, mas também por outras interações, tais como, interação hidrofóbica cauda-cauda e/ou interações entre anéis piridínicos formando bicamadas incompletas e/ou monocamadas condensadas, respectivamente.
\end{abstract}

The adsorption of cetyltrimethylammonium (CTA) bromide and cetylpyridinium (CP) chloride on $\mathrm{Na}^{+}$-rich montmorillonite (MMT) was studied. An ad hoc isotachophoretic (ITP) method was developed for the simultaneous and rapid determination of the cationic surfactants (CSs) adsorbed. In order to decrease the detection limits, ITP was on-line coupled with capillary zone electrophoresis. Adsorption data were analysed by their fitting with adsorption isotherms. The adsorption of $\mathrm{CP}$ is well described by the Langmuir isotherm. It indicates the monolayer arrangement of $\mathrm{CP}$ on the MMT surface. In case of the CTA data, the best fitting LangmuirFreundlich model with the power constant $r<1$ was found. It can be explained by the CTA interactions because of its intercalation into the MMT interlayer space.

Keywords: adsorption isotherms, montmorillonite, cetyltrimethylammonium, cetylpyridinium, capillary isotachophoresis

\section{Introduction}

Phyllosilicates are layered silicates in which the $\mathrm{SiO}_{4}$ tetrahedra are linked together in infinite two-dimensional sheets and are condensed with layers of $\mathrm{AlO}_{6}$ or $\mathrm{MgO}$ octahedra in the ratio $2: 1$ or $1: 1$. The negatively charged layers attract positive cations (e.g. $\mathrm{Na}^{+}, \mathrm{K}^{+}, \mathrm{Ca}^{2+}, \mathrm{Mg}^{2+}$ ) which can hold the layers together. Their large cation exchange capacities enable them to adsorb heavy metals and also to be modified with quaternary salts ${ }^{1}$ including cationic surfactants. ${ }^{2}$ One of the exceptional properties of such prepared organo-phyllosilicates is their ability to sorb hydrophobic organic contaminants, such as chlorinated phenols, ${ }^{3,4}$ perchlorethylene, naphtalene and phenanthrene, ${ }^{5-7}$ aniline ${ }^{8}$ phenol $^{9}$ etc. The retention of inorganic oxyanions, such as chromate, nitrate, and

*e-mail: petr.praus@vsb.cz arsenate, on organo-kaolinite ${ }^{10}$ and organo-clinoptilolite ${ }^{11}$ has been studied recently, as well.

The usual methods for the determination of cationic surfactants are ion-association titration, ${ }^{12}$ extraction spectrometry, ${ }^{13}$ high performance liquid chromatography with reversed ${ }^{14,15}$ and ion-pair normal phase, ${ }^{16}$ and also capillary zone electrophoresis (CZE). ${ }^{17-24}$ The application of capillary isotachophoresis for the separation of C8-C20 cationic surfactants has been already reported by Tribet et $a l .{ }^{25,26}$ and Praus. ${ }^{27}$

The aim of this work was to study the CSs adsorption on montmorillonite. Cetyltrimethylammonium bromide and cetylpyridinium chloride, chosen as the typical cationic surfactants, were determined by an ITP method developed for this purpose. The prepared montmorillonite samples modified with the CSs will be used as sorbents for the retention of toxic compounds from air and water. ${ }^{28}$ 


\section{Experimental}

\section{Reagents}

The used chemicals were of the analytical reagent grade: ammonium acetate, lithium nitrate, glacial acetic acid, ethanol 96\% (all from Lachema, Czech Republic), $\beta$-alanine (Serva, Germany), cetyltrimethylammonium bromide and cetylpyridinium chloride (Sigma, USA). Twice distilled and deionised water by a mixed-bed ionexchanger (Watrex, Czech Republic) was used for the preparation of all solutions. The certified reference materials of metal ions in the concentrations of $1 \mathrm{~g} \mathrm{~L}^{-1}$ were purchased from Analytica (Czech Republic).

\section{Apparatus}

An isotachophoretic analyzer EA 102 (Villa-Labeco, Slovakia) in the column-coupling configuration was employed. The capillaries were made from a fluorinated ethylene-propylene copolymer (FEP): a pre-separation capillary $90 \times 0.8 \mathrm{~mm}$ I.D. and an analytical capillary 200 $\times 0.3 \mathrm{~mm}$ I.D. Both capillaries were equipped with contact conductivity detectors and, in addition, analytical capillary was equipped with an UV detector. The driving current in the pre-separation capillary was set at $200 \mu \mathrm{A}$ and reduced at $100 \mu \mathrm{A}$ prior to detection. In the analytical capillary the driving current was kept at $25 \mu \mathrm{A}$ in all experiments. Samples were injected through a $30 \mu \mathrm{L}$ sampling loop.

The $\mathrm{pH}$ values of the operational systems were measured with a pH metre WTW InoLab (Weilheim, Germany). An UV-Vis spectrometer Lambda 25 (Perkin Elmer, USA) was used for the determination of CP.

\section{Intercalation of montmorillonite with CTA and CP}

A $\mathrm{Na}^{+}$-rich Montmorillonite type Wyoming $\left(\mathrm{Al}_{2.90} \mathrm{Mg}_{0.59} \mathrm{Fe}^{3+}{ }_{0.49} \mathrm{Ti}_{0.01}\right)_{3.99}\left(\mathrm{Si}_{7.92} \mathrm{Al}_{0.08}\right)_{8.0} \mathrm{O}_{20}(\mathrm{OH})_{4}$ with exchanged capacity of 0.9 mequiv. $\mathrm{g}^{-1}$ was used for the adsorption of CTA and CP. These cationic surfactants were dissolved in a 50:50 (v/v) mixture of water and ethanol, MMT was added and this suspension was shaken vigorously for 2 hours. The suspension was centrifuged for 20 minutes and the supernatant was analysed. The adsorption experiments were performed at the laboratory temperature of $22 \pm 2{ }^{\circ} \mathrm{C}$.

\section{Analysis of equilibrium data}

Adsorption data were fitted using several adsorption isotherms describing the monolayer adsorption: Langmuir, Freundlich, and Langmuir-Freundlich (Sips). Non-linear regressions were performed by the Gauss-Newton method. The best fitting model was chosen according the statistical regression criteria: regression coefficient (R), Akaike information criterion (AIC) and mean error of prediction (MEP).

\section{Langmuir isotherm}

The Langmuir isotherm was theoretically derived supposing that the adsorption takes place on fixed homogenous absorption sites of equal energy forming a monolayer surface coverage, with no interactions between molecules adsorbed. The Langmuir model can be described by the equation

$$
a=a_{m} \frac{k c_{e}}{1+k c_{e}}
$$

where $\mathrm{a}\left(\mathrm{mmol} \mathrm{g} \mathrm{g}^{-1}\right)$ and $\mathrm{c}_{\mathrm{e}}\left(\mathrm{mmol} \mathrm{L}^{-1}\right)$ are the equilibrium concentration of adsorbate on a adsorbent surface and the adsorbate concentration in solution, respectively. The constant $\mathrm{k}$ is the equilibrium constant which represents the affinity between adsorbate and adsorbent and $a_{m}$ is the maximum amount adsorbed on surface.

\section{Freundlich isotherm}

The Freudlich isotherm is strictly the empirical model. The adsorbent concentration is a power function of the adsorbate concentration as follows:

$a=K c_{e}{ }^{1 / p}$

where $\mathrm{K}$ and $\mathrm{p}$ are the Freundlich and the power constant, respectively. In spite of the Langmuir model it does not show a saturation of adsorbent surface. The sorbed amount increases indefinitely with the concentration in solution. It was found by Halsey ${ }^{29}$ that the Freundlich isotherms holds for the heterogenous surface when adsorption energy is reciprocal to $\log \Theta$, where $\Theta$ is $a / a_{m}$ (a degree of surface coverage).

\section{Langmuir-Freundlich (Sips) isotherm}

The Langmuir-Freundlich isotherm is simple generalization of both isotherms. It was derived by Sips ${ }^{30}$ in 1950 who considered adsorption energy ranging from 0 to $\infty$. It holds for this isotherm:

$$
a=a_{m} \frac{\left(k c_{e}\right)^{r}}{1+\left(k c_{e}\right)^{r}}
$$


where the symbols are the same as in the Langmuir isotherm and $r$ is the power constant. As this equation has three fitting constants it much better describes the adsorption including adsorption binding interactions among adsorbing compounds. ${ }^{31}$ For independent noninteracting adsorption sites corresponding to the Langmuir model, the value $r$ is 1 . When $r>1$, positive cooperativity is assumed, while when $0<\mathrm{r}<1$ negative adsorption cooperativity can be expected.

\section{Data processing}

Isotachopherograms and electropherograms were recorded and evaluated by using the programme ITPPro32 (KasComp, Ltd., Slovakia). The non-linear regression and all statistical calculations made at the $\alpha=0.05$ significance level were performed by the program QC.Expert 2.5 (Trilobyte Statistical Software, Czech Republic).

\section{Results and Discussion}

\section{ITP method development}

Composition of the ITP electrolytes (Table 1) was adopted from the previous work. ${ }^{27}$ Ethanol (EtOH) has been found to avoid the CTA micellization in its concentrations up to $2 \mathrm{mmol} \mathrm{L}^{-1}$ caused by the ITP concentration effect. The initial series of ITP experiments were performed in leading (LE) and terminating (TE) electrolytes containing $40 \%$ (v/v) of EtOH. No CTA and $\mathrm{CP}$ micelles were recorded but this amount of EtOH did not prevent the surfactant adsorption on capillary surface which was indicated by the low repeatability of ITP measurements. Therefore, the EtOH content was increased at cca $50 \%$ and under these conditions no adsorption of both surfactants was observed.

This leading electrolyte enables the separation of not only CTA or CP but also of the metal cations, such as $\mathrm{Na}^{+}, \mathrm{Ca}^{2+}, \mathrm{Mg}^{2+}$ and $\mathrm{Li}^{+}$(Figure 1). Lithium was used as an internal standard. Ethanol acts as a suitable medium for the separation of these metals without using any complex forming additives. ${ }^{32}$ The only exception is $\mathrm{K}^{+}$ which makes a mixed zone with $\mathrm{NH}_{4}^{+}$. It could be theoretically determined from the leading zone prolongation but, unfortunately, precision of this procedure was poor. From Figure 1 it also follows that the CTA and CP mobilities are very close. Because of the thermal zone distortion resulting from the reduced ion mobilities in ethanolic electrolytes, ${ }^{33}$ the driving current was reduced at $100 \mu \mathrm{A}$ prior to detection. Thus, one ITP run takes about 5.5-7 minutes.
Table 1. Electrolyte systems used for the ITP and ITP-CZE separations

\begin{tabular}{lcc}
\hline Parameter & Leading electrolyte & Terminating electrolyte \\
\hline Cation & Ammonium & $\beta$-alanine \\
Concentration & $5 \mathrm{mmol} \mathrm{L}^{-1}$ & $5 \mathrm{mmol} \mathrm{L}$ \\
Counter ion & Acetate & Acetate \\
Concentration & $2.8 \mathrm{mmol} \mathrm{L}^{-1}$ & $2.8 \mathrm{mmol} \mathrm{L}$ \\
Solvent & Water-ethanol $(50: 50)$ & Water-ethanol $(50: 50)$ \\
\hline
\end{tabular}

\section{ITP method validation}

The ITP method was validated before its application. The calibration equations and some another validation parameters are summarised in Table 2. The limits of detection (LOD) and quantification (LOQ) were estimated from the calculated standard deviations of the blanks linearly extrapolated from calibration data. In order to reduce the LODs and LOQs of both the surfactants, ITP was on-line coupled with CZE performed in an analytical capillary.

In this separation mode (ITP-CZE), isotachophoreticaly migrating compounds are stacked in sharp zones, transferred into the CZE capillary where are destacked and detected. Advantages of the ITP-CZE combination are the high separation capacity of ITP and the high separation efficiency and sensitivity of

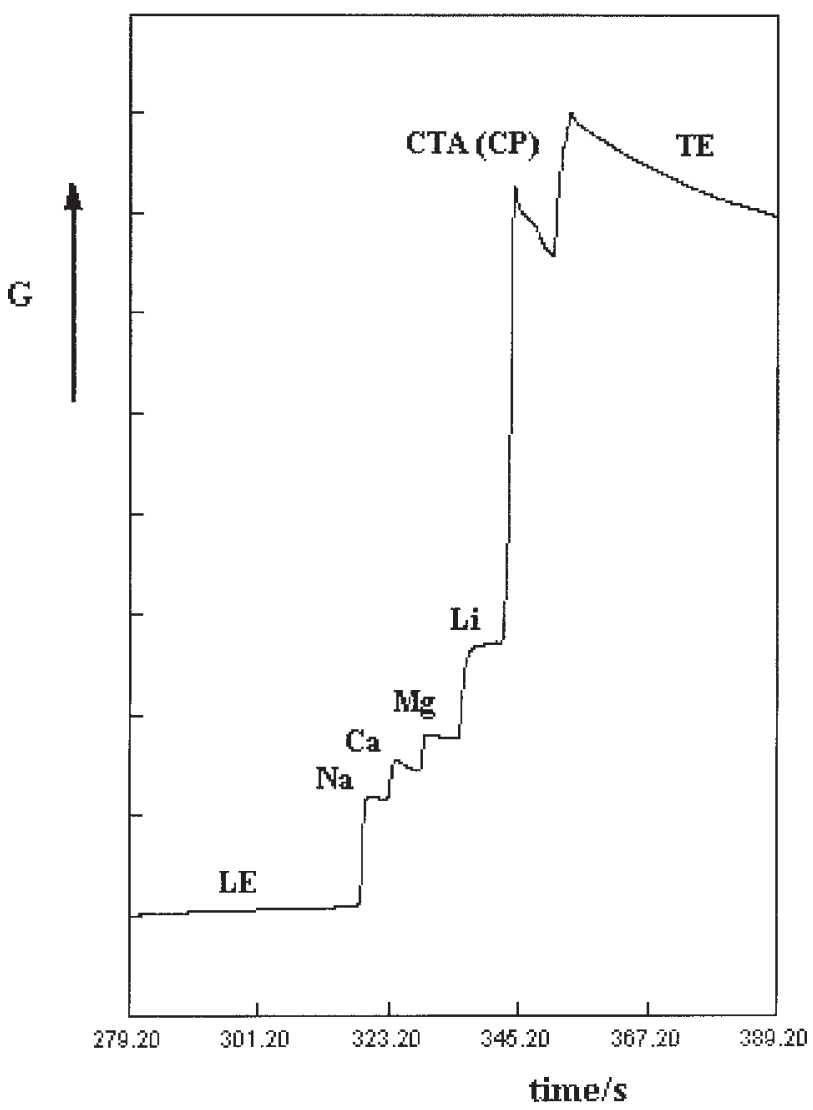

Figure 1. ITP separation of an mixture of cationic surfactants and metal ions. LE-leading ion, TE-terminating ion, G-conductivity. 
Table 2. ITP calibration parameters

\begin{tabular}{llllll}
\hline Analyte & Regression equations & LOD & LQD & UCL & R \\
\hline CTA & $\mathrm{y}=-0.89+106.6 \times(\mathrm{n}=10)$ & 0.02 & 0.03 & 0.80 & 0.9994 \\
$\mathrm{CP}$ & $\mathrm{y}=0.11+86.2 \times(\mathrm{n}=16)$ & 0.02 & 0.04 & 0.80 & 0.9989 \\
$\mathrm{CTA}^{\mathrm{a}}$ & $\mathrm{y}=-254+88494 \mathrm{x}(\mathrm{n}=6)$ & 0.005 & 0.007 & 0.05 & 0.9984 \\
$\mathrm{CP}^{\mathrm{b}}$ & $\mathrm{y}=-1552+462805 \mathrm{x}(\mathrm{n}=8)$ & 0.004 & 0.005 & 0.08 & 0.9986 \\
\hline
\end{tabular}

Note: n-number of repeated analyses, y-zone length (s), x-concentration, UCL-upper calibration limit, R-regression coefficient, ${ }^{a}$ the conductivity and ${ }^{b} \mathrm{UV}$ detection in the analytical capillary of ITP-CZE. All concentration units are given in $\mathrm{mmol} \mathrm{L}^{-1}$.

CZE. ${ }^{34-37}$ The ITP-CZE system was realized by filling the pre-separation and analytical capillaries with leading and terminating electrolytes, respectively. The ITP-CZE determination of the low CTA concentrations was limited by the presence of a close migrating impurity originated from the terminating electrolyte. On the other hand, the $\mathrm{CP}$ separation was disturbed by no compounds if an UV detection at $\lambda=259 \mathrm{~nm}$ (a maximum of the $\mathrm{CP}$ absorption band) was applied. Therefore, the ITP-CZE system was used only for the analyses of the low concentrations of CP. A typical ITPCZE record is demonstrated in Figure 2.

Precision and accuracy of ITP and ITP-CZE are summarized in Table 3. The inter-day precision calculated from the analyses performed during one week $(n=7)$ were up to $\mathrm{RSD}=2.80 \%$ for all separands. As no certified reference material (CRM) of cationic surfactants was available, the accuracy of the CTA and CP determinations were expressed as their recovery from spiked tap water. The ITP and ITP-CZE results of the CP analyses were also confirmed by UV spectrometry at $\lambda=259 \mathrm{~nm}$. These results indicate that the both ITP and ITP-CZE method are acceptable for the determination of the CSs and the metal ions at this adsorption study.

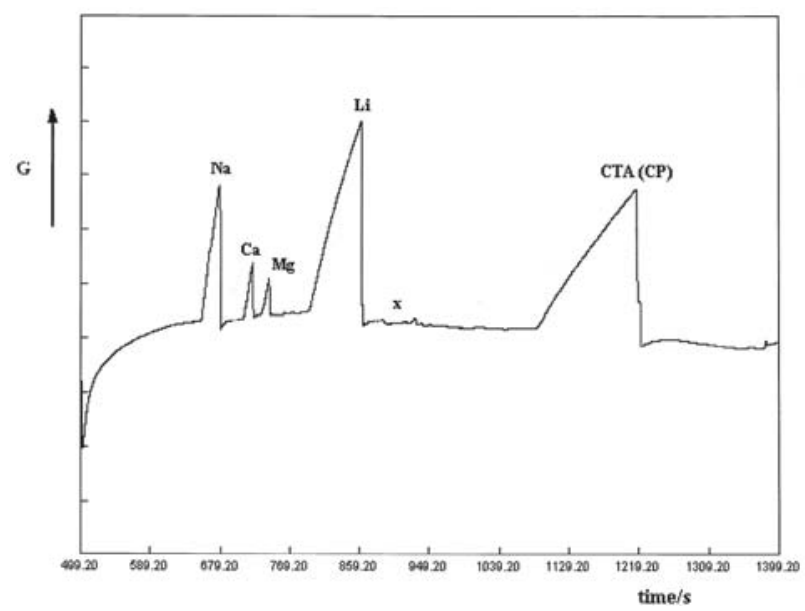

Figure 2. CZE separation of the cationic surfactants together with the metal ions using a conductivity detector. G-conductivity, x-unknown compounds.
Table 3. Intra-day precision and accuracy of the ITP and ITP-CZE methods

\begin{tabular}{lccccc}
\hline Analyte & Added & Found & Recovery/(\%) & $\mathrm{n}$ & $\mathrm{RSD} /(\%)$ \\
\hline CTA & 0.20 & 0.197 & 98.65 & 7 & 4.45 \\
& 0.40 & 0.395 & 98.75 & 6 & 2.91 \\
$\mathrm{CP}$ & 0.60 & 0.580 & 96.62 & 7 & 2.21 \\
& 0.20 & 0.204 & 101.95 & 6 & 1.10 \\
& 0.40 & 0.415 & 103.65 & 7 & 1.05 \\
$\mathrm{CP}$ (ITP-CZE) & 0.60 & 0.591 & 98.08 & 8 & 2.12 \\
& 0.010 & 0.0096 & 95.60 & 5 & 3.19 \\
& 0.050 & 0.0496 & 99.14 & 7 & 3.43
\end{tabular}

Note: RSD, relative standard deviation, all concentration units are given in $\mathrm{mmol} \mathrm{L}^{-1}$.

Adsorption of the cationic surfactants on montmorillonite

All adsorption (batch) experiments were performed in water-methanol $(50: 50, \mathrm{v} / \mathrm{v})$ solutions to avoid micellization of the cationic surfactants. In order to understand adsorption mechanisms, the adsorption isotherms were constructed. These equilibrium data were analysed by their fitting with the isotherm models described above. The non-linear regression results are given in Table 4.

According to the $\mathrm{R}$ and AI criteria, the LangmuirFreundlich isotherm is the most suitable model characterizing the adsorption of CTA on MMT (Figure 3). In the case of $\mathrm{CP}$, all regression criteria show that both Langmuir and Langmuir-Freundlich models are potential for the experimental data smoothing. In addition, the power constant $r$ is statistically equal 1 (see the $r$ confidence interval) which means that the LangmuirFreundlich can be replaced by the simpler Langmuir one. The evaluation of the best fitting isotherms could elucidate how the cationic surfactants are adsorbed on the montmorillonite surface.

CP was adsorbed in agreement with the Langmuir model which was theoretically derived supposing no interactions between compounds forming monolayers on solids. On the other hand, the adsorption of CTA is better described by the Langmuir-Freundlich isotherm 
Table 4. Results of the adsorption isotherms fitting

\begin{tabular}{lccc}
\hline & & Adsorption models - adsorption of CTA (n=11) \\
\cline { 2 - 4 } Parameter & Langmuir & Freundlich & Langmuir-Freundlich \\
\hline$a_{m}$ & $0.5288 \pm 0.0251$ & $0.5514 \pm 0.0462$ & $0.5564 \pm 0.0452$ \\
$\mathrm{k}$ & $100.5 \pm 46.3$ & - & $100.1 \pm 47.1$ \\
$\mathrm{p} / \mathrm{r}$ & - & $9.326 \pm 4.253$ & $0.7008 \pm 0.2680$ \\
$\mathrm{R}$ & 0.9579 & 0.8824 & 0.9769 \\
MEP & 0.0021 & 0.0034 & 0.0118 \\
AIC & -76.68 & -65.80 & -81.16 \\
\hline & & Adsorption & models - adsorption of CP (n=12) \\
Parameter & Langmuir & Freundlich & Langmuir-Freundlich \\
$a_{m}$ & $0.6408 \pm 0.0231$ & $0.6769 \pm 0.0608$ & $0.6574 \pm 0.0372$ \\
$\mathrm{k}$ & $139.6 \pm 33.1$ & - & $131.5 \pm 37.6$ \\
$\mathrm{p} / \mathrm{r}$ & - & $7.866 \pm 2.652$ & $0.8137 \pm 0.2503$ \\
$\mathrm{R}$ & 0.9842 & 0.9147 & 0.9868 \\
MEP & 0.0011 & 0.0054 & 0.0014 \\
AIC & -90.6 & -69.1 & -90.9 \\
\hline
\end{tabular}

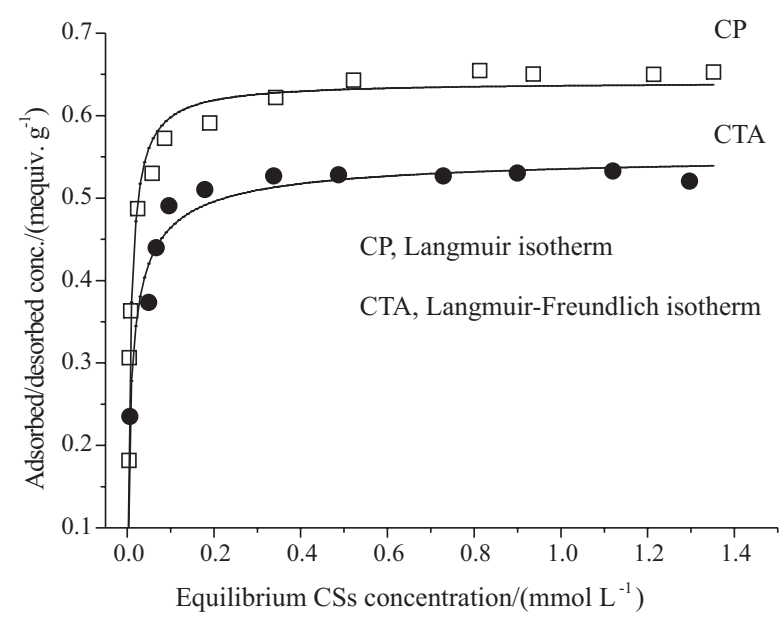

Figure 3. Adsorption data fitting with the Langmuir and LangmuirFreundlich isotherms.

with $r<1$ which supposes some types of interactions between adsorbing molecules. Such interactions can be ascribed to the forces among cationic surfactant intercalated into the MMT interfacial space. Thus the significant interactions of CTA would be explained by its significant intercalation.

Intercalation of montmorillonite with CTA and CP has been already modelled by means of molecular dynamic simulations. ${ }^{38,39}$ Both CTA and CP were suggested to be arranged within interlamellar space in a liquid like disordered monolayer. The stronger intercalation of CTA was predicted as well as confirmed experimentally. ${ }^{39}$ Also in our recent work $^{40}$ we have found that the basal spacings $d_{001}$ of the MMT saturated with CTA exhibited the higher basal spacing $\left(\mathrm{d}_{001}=1.75\right)$ than in the case of $\mathrm{CP}\left(\mathrm{d}_{001}=1.66\right)$.
These isotherm analyses results also imply that both $\mathrm{CP}$ and CTA are arranged in their monolayers on the external MMT surface. It agrees with our concept $t^{40}$ based on molar balance between the surfactants adsorbed and the metal ions desorbed from MMT saturated with $\mathrm{CP}$ and CTA. Unlike CTA monolayers created by means of ion-exchange mechanisms, the $\mathrm{CP}$ monolayers could be additionally formed via interactions of the pyridinium headgroups, such as the induced interactions between pyridinium rings and polar silicate face and the $\pi-\pi$ interactions between neighbouring pyridinium rings. In order to confirm this idea, the molecular simulations of the cationic surfactants adsorption on the external MMT surface will be tested in the near future.

\section{Conclusions}

In this paper, the physico-chemical study of the CTA and $\mathrm{CP}$ adsorption on montmorillonite was carried out. For this purpose, the ITP and ITP-CZE methods were developed and validated. Using the ethanolic electrolytes, ITP was found to be an effective separation technique for the analyses of CTA and CP in a very short time.

The adsorption equilibrium data were fitted with the common adsorption isotherms, such as Langmuir, Freundlich, and Langmuir-Freundlich ones. The CP and CTA adsorption was best described by the Langmuir and Langmuir-Freundlich models, respectively. These results indicate the monolayer arrangement of the both surfactants on the MMT external surface. Additionally, the CTA significant interactions (the power constant $\mathrm{r}<1$ ) can be explained by its intercalation which takes 
place in higher extent than in the case of CP. The results of this physico-chemical study will be completed by molecular simulations in the future research.

\section{Acknowledgment}

This work was supported by the Ministry of Education, Youth and Sport of the Czech Republic (MSM 6198910016).

\section{References}

1. Stevens, J.J.; Anderson, S.J.; Clays Clay Miner. 1996, 44, 132.

2. Srinivasan, K.R.; Fogler, H.S.; Clays Clay Miner. 1990, 38, 277.

3. Boyd, S.A.; Sun, S.; Lee, J.F.; Mortland, M.M.; Clay. Clay. Miner. 1988, 36, 125.

4. Michot, L.J.; Pinnavaia, T.J.; Clays Clay Miner. 1991, 39, 634.

5. Burris, D.R.; Antworth, C.P.J.J.; J. Contam. Hydrol. 1992, 10, 325.

6. Lee, S.Y.; Kim, S.J.; Chung, S.Y.; Jeong, C.H.; Chemosphere 2004, 55, 781 .

7. El-Nahhal, Y.Z.; Safi, J.M.; J. Colloid Interface Sci., 2004, 269 , 265.

8. Li, Z.; Burt, T.; Bowman, Z.S.; Environ. Sci. Technol. 2000, 34, 3756.

9. Jiang, J.Q.; Cooper, C.; Ouki, S; Chemosphere 2002, 47, 711.

10. Li, Z.; Bowman, R.S.; Water Res. 2001, 35, 3771.

11. Li, Z.; Bowman, R.S.; Environ. Sci. Technol. 1997, 31, 2407.

12. Sakai, T.; Teshima, N.; Takatori, I.; Anal. Sci. 2003, 19, 1323.

13. Li, S.; Zhao, S.; Anal. Chim. Acta 2004, 501, 99.

14. Heinig, K.; Vogt, C.; Gerhard, W.; J. Chromatogr., A 1996, 745 , 281.

15. Harrison, Ch.R.; Lucy, Ch.; J. Chromatogr., A 2002, 956, 237.

16. Norberg, J.; Thordarson, E.; Mathiasson, L.; Jönsson, Å.; J. Chromatogr., A 2000, 869, 523.

17. Herrero-Martínez, J.M.; Simó-Alfonso, E.F.; Mongay-Fernández, C.; Ramis-Ramos, G.; J. Chromatogr., A 2000, 895, 227.

18. Heinig, K.; Vogt, C.; Gerhard, W.; Fresenius J. Anal. Chem. 1997, 358, 500.
19. Kharitonova, K.; Rudnev, A.; Ivanova, N.; Progr. Colloid. Polym. Sci. 2004, 125, 184.

20. Piera, E.; Erra, P.; Infante, M.R.; J. Chromatogr. A 1997, 757, 275.

21. Schöftner, R.; Buchberger, W.; Malissa H.; J. Chromatogr. A 2001, 920, 333.

22. Öztenkin, N.; Erim, F.B.; J. Pharm. Biomed. Anal. 2005, 37, 1121.

23. Capote, F.P.; de Castro, M.D.L.; Electrophoresis 2005, 26, 2283.

24. Taylor, R.B.; Toasaksiri, S.; Reid, R.G.; J. Chromatogr. A 1998 , $798,335$.

25. Tribet, C.; Gabouriaud, R.; Gareil, P.; Electrochim. Acta 1992, $37,2769$.

26. Tribet, C.; Gabouriaud, R.; Gareil, P.; J. Chromatogr. 1992, 609, 381.

27. Praus, P.; Talanta 2005, 65, 281.

28. Zhu, L.; Tian, S.; Shi, Y.; Clays Clay Miner. 2005, 53, 123.

29. Halsey, G.; Advan. Catal. Relat. Subj. 1952, 4, 259.

30. Sips, R.; J. Chem. Phys, 1950, 18, 1024.

31. Sharma, S.; Agarwal, G.P.; Anal. Biochem. 2001, 288, 126.

32. Valášková, I.; Havránek, E.; J. Chromatogr. A 1999, 836, 201.

33. Everaerts, F.M.; Beckers, J.L.; Verheggen, Th.P.E.M.; Isotachophoresis, Elsevier: Amsterdam, 1976.

34. Kaniansky, D.; Marák, J.; J. Chromatogr. 1990, 498, 191.

35. Křivánková, L.; Gebauer, P.; Thormann, W.; Mosher, R.; Boček P.; J. Chromatogr. 1993, 638, 119.

36. Křivánková, L.; Gebauer, P.; Boček, P.; J. Chromatogr., A 1995, $716,35$.

37. Kaniansky, D.; Marák, J.; Laštinec, J.; Reijenga, J.C.; Onuska, F.I.; J. Microcol. Sep. 1999, 11, 141.

38. Hackett, E.;Manias, E.; Giannelis, E.P.; J. Chem. Phys. 1998, 108,7410

39. Pospíšil, M.; Čapková, P.; Měřínská, D.; Maláč, Z.; Šimoník, J.; J. Colloid Interface Sci. 2001, 236, 127.

40. Praus, P.; Turicová, M.; Študentová, S.; Ritz, M.; J. Colloid Interface Sci. 2006, 304, 29.

Received: June 26, 2006

Web Release Date: March 23, 2007 